\title{
THE VSAS APPROACH GIVES THE BEST MPPT FOR SOLAR ENERGY SOURCES (RES)
}

\author{
Nacer K. ${ }^{1}$, M'Sirdi N. K. ${ }^{2}$, Rabhi A. ${ }^{3}$, Nehme B. ${ }^{4}$ \\ ${ }_{1}$ Laboratory of Systems and Information Sciences of Aix Marseille University (LSIS - AMU), \\ ${ }^{2}$ CNRS UMR 7296, Domaine Universitaire Saint-Jerome, Avenue Escadrille Normandie-Niemen, \\ 13397 Marseille Cedex 20, France. \\ ${ }^{3}$ MIS, Laboratory of Modeling, Information and Systems, University of Picardie Jules Verne Amiens, France \\ Authors are members of the HYRES Lab and the RMEI Network. \\ ${ }^{4}$ Département de Génie Électrique et Électronique, Faculté d'Ingénierie, Université Saint-Esprit de Kaslik, \\ B.P. 446 Jounieh, Mont Liban - Liban.
}

\begin{abstract}
More and more MPPT (Maximum Power Point Tracking) algorithms are in competition to maximize energy extracted from PV systems. This paper shows how to get the best algorithm (the most simple, fast and robust). VSAS (Variable Structure Automatic Systems) control methodology is applied to develop the control algorithm, to clarify the rationale behind and get the best optimization algorithm.
\end{abstract}

Keywords - Maximum Power Point Tracking, Renewable Energy Sources, Perturb and Observe, IncCond, Hill Climbing.

\section{INTRODUCTION}

The PV system operation principle needs a polarization depending on the weather to fix the operation point leading to extraction of the maximum power. The Renewable Energy Systems (RES) include commutations and discontinuities; this is one kind of Variable Structure System (VSS). However, the behaviour of the conversion systems of this kind of renewable energy is VSAS (Variable Structure Automatic Systems)[MsirdiEFEA14] and highly dependent on variations in climate parameters, such as temperature and irradiation.

The MPPT algorithms are necessary to maximize, at each time instant, the produced power. Several techniques have been designed to search this optimal Maximum Power Point (MPP). In the literature, more and more MPPT (Maximum Power Point Tracking) algorithms are in competition to maximize energy extracted from PV systems.

The maximum performance of a photovoltaic system depend, of course, on good weather conditions, but needs also appropriate MPPT algorithm [Mutoh, NianChun]. The great majority of
MPPT control strategies are based on the (steady state) characteristics of PV panels, such as I-V or P$\checkmark$ plots, the duty cycle ratio control and sometimes using look-up tables [Amei]. A lot of MPPT techniques are well established in the literature. There are several methods: voltage feedback method, perturbation and observation method, linear approximation method, incremental conductance method, hill climbing method, actual measurement method, fuzzy control method and so on [Ting-Chung, Tavares, Hua Lin, Fangrui, ChihChuanHua, Weidong]. In general, there exist four types of MPPT techniques:

- the PV operation point perturbation and observation (PO) based algorithms in order to get the direction of tracking the MPP.

- the hill-climbing algorithm which makes a perturbation in duty cycle to reach the apex of the characteristics.

- the incremental conductance (InCond) algorithm which periodically checking heslope (conductance) of the P-V curve [Liu].

- the constant voltage algorithm based on keeping constant the ratio between the PV voltage at the maximum power and the open circuit voltage (Voc) value; In this method the effect of solar irradiance variations is neglected [Hohm].

In[lbrahimHoussiny, Amei], Ibrahim and Houssing use a look-up table to track, when other author prefer the use of a dynamic MPP tracker to PV appliances [MidyaKerin]. A single-stage MPP controller using the slope the power versus voltage, like has been done in [KuoLiangChen]. In [Hua Lin] a 
DSP chips is used to implement the PO MPPT in order to get maximum power. They, also try to improve the efficiency of the $\mathrm{PO}$ and $\mathrm{HC}$ methods.

In [Fangrui], the time response of $\mathrm{PO}$ [ChihChuanHua]and $\mathrm{HC}$ methods [Fangrui, Weidong, Hohm]are compared for a grid connected system. The PO method can fail under rapidly changing atmospheric conditions. Several research activities have been carried out to improve the traditional Hillclimbing and P\&O methods. Reference [Xiao] proposes to use three measurement points to compute MPP.

The method compares the obtained power measurement to the two preceding points before choosing the perturbation sign. In [KuoLiangChen] the authors propose a two stage algorithm that offers faster tracking in the first stage and more accurate tracking in the second stage. To prevent divergence from MPP, they use a modified adaptive algorithm.

Table 1. Parameters Definition

\begin{tabular}{|c|c|c|}
\hline Symbol & Units & Definition \\
\hline $\mathrm{q}$ & $\mathrm{q}=1.6 .10-19 \mathrm{C}$ & The electron charge \\
\hline $\mathrm{n}$ & diode non-ideality factor & \\
\hline $\mathrm{K} \mathrm{B}$ & $1.38065 \cdot 10-23 \mathrm{~N} \cdot \mathrm{m} / \mathrm{K}$ & the Boltzmann's constant \\
\hline $\mathrm{STC}$ & at $\left(1 \mathrm{~kW} / \mathrm{m} 2,25^{\circ} \mathrm{C}\right)$ & Standard Test condition \\
\hline $\mathrm{I} \mathrm{SC}$ & $\mathrm{A}$ & Short Circuit Current \\
\hline I SC,STC & $\mathrm{A}$ & Short circuit current at STC \\
\hline $\mathrm{V} \mathrm{OC}$ & $\mathrm{V}$ & Open Circuit Voltage \\
\hline $\mathrm{K} 0$ & $\%$ calculated for ISC & Temperature coefficient \\
\hline $\mathrm{G}$ & $\mathrm{W} / \mathrm{m} 2$ & Solar radiation \\
\hline $\mathrm{T}$ & in Kelvin ${ }^{\circ} \mathrm{K}$ & the cell temperature \\
\hline $\mathrm{T} 1$, ref & at $1 \mathrm{~kW} / \mathrm{m} 2,298 \mathrm{~K}\left(25^{\circ} \mathrm{C}\right)$ & Reference temperature \\
\hline $\mathrm{T} 2$, ref & $\mathrm{K}$ & Temperature at 2nd STC \\
\hline $\mathrm{V}$ ref & $\mathrm{V}$ ref $=5 \mathrm{~V}$ & Reference voltage \\
\hline
\end{tabular}

In [Tina]Tina et. al. proposed a mathematical model for the electrical-thermal coupling of a PV module with ambient temperature, wind speed, wind direction, relative humidity and electrical operating point (voltage and current values). An MPP tracking based on Dual boost converter is developed using fuzzy logic in [Veerachary]. Artificial neural network (ANN), trained offline with a gradient descent algorithm using a back-propagation have been used by Kaiser et. al.
[Kaiser] to generate (online) the reference voltage for MPPT control, in a solar electric vehicles. Another approach based on variable structure control is applied to a buck converter in [MiaoJie]. In [TingChung],

the authors study and compare three maximum power point tracking (MPPT) algorithms, under different climate conditions, in a photovoltaic simulation: the algorithms of perturbation and observation (PO), incremental conductance (INC) and hill climbing $(\mathrm{HC})$, respectively (see also [Hohm]). They show that the photovoltaic simulation can track the maximum power accurately using the three MPPT algorithms. PO algorithm has fast dynamic response and well regulated $\mathrm{PV}$ output voltage than $\mathrm{HC}$ algorithm. Since the INC algorithm is more complex, the time response of INC is a little longer.

All of the MPPTs are based on the convex nature of the power characteristic curve and ignore that the characteristic can change in time when the temperature or irradiation changes[Shaefer, Kim]. As the weather conditions change during time, the Maximum Power Point varies also with time. The maximum power point (MPP) changes from one curve to another, with solar irradiation or load variations.

The paper is organized as follows. Section 1 gives the problem formulation and recalls most used algorithms used for MPPT. The second section presents PV system equations and features. Section three introduces our new algorithm design approach. We compare their results with the widely used MPPT algorithms; performance is evaluated considering different actual solar irradiation measured variations. The fourth section gives a conclusion and proposes perspectives.

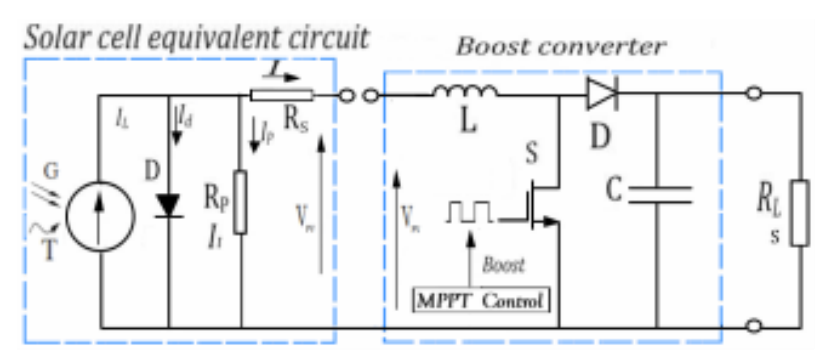

Fig .1. Equivalent circuit model of PV panel 


\section{PV SYSTEMS CONTROL}

\section{A. Solar Energy Sources}

In this section we present the models of the PV systems. The simulation of the energy behavior of RES (Renewable Energy Source) is developed and several control methods and parameters can be analyzed. The goal is to obtain a good model of the process and to achieve a realistic simulation to enable us to check and validate our approach of Optimal MPPT and control.

\section{The Solar irradiation Model}

The electric power operating by a PV panel depends on the irradiation intensity of the sun shining, and the temperature of the PV cells. The simplest solar radiation, perturbation free, model that can be used is the following, from (roughly) 7h$19 \mathrm{~h}$, the period of sunshine. At the top of the sinusoid, the maximum power is assumed to be $1 \mathrm{kw} / \mathrm{m}^{2}$, at the time 13 hours. The sunless period is $19 \mathrm{~h}-31 \mathrm{~h}$ [schijndel1, Sallem]. Note that the wave is assumed piecewise sinusoidal. The solar radiation is represented by the following expression:

$$
\mathrm{G}_{S}=\left\{\mathrm{G}_{S-p i c} \sin \left(\frac{2 \pi \mathrm{t}}{3600}\right) \text { if } \mathrm{t} \in[7 \mathrm{~h}, 19 \mathrm{~h}]\right.
$$

The electric diagram is equivalent to an average PV cell as shown in figure 1

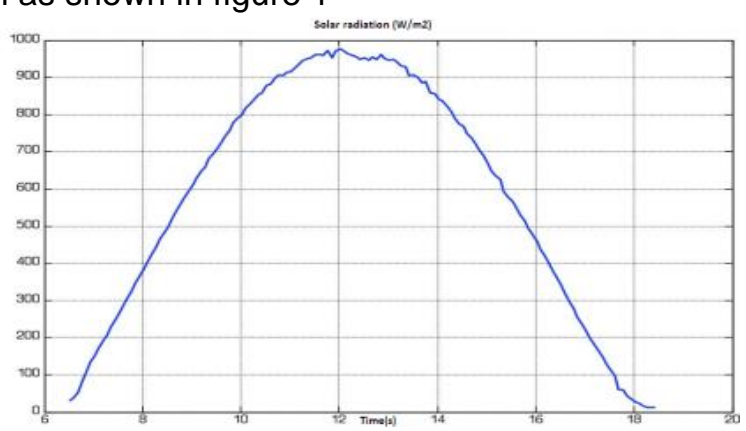

(a)

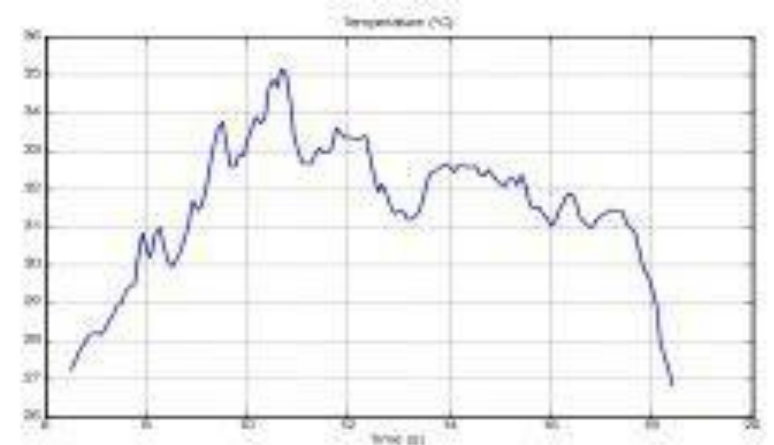

(b)
Fig .2. a) Measurement of Solar irradiance taken for a day;

b) Temperature taken for a day

\section{Photovoltaic Systems Model and characteristics}

A PhotoVoltaic Generator consists of a group of PV modules electrically connected in series or parallel or series-parallel combinations with each other in a RES to generate required currents and voltages [MsirdiEFEA14, Liu].

The model is a photo-current source IL one diode with as reverse saturation current 10 , and a serial resistance RS , representing the PV cell resistance. The circuit is connected to the load ( R L ) trough a converter in order to adjust (adapt) the operating voltage and current of the PV panel at optimal values to maximize the harnessed power and transmit it. The control has to tracks the Maximum Power Point.

The equations describing the $\mathrm{I}(\mathrm{V})$ relationship between the current and voltage of a solar cell are given by (2), with the parameters defined in Table1 [Shaefer, Hsiao, Walker].

$$
\begin{aligned}
& I=I_{L}-I_{0}\left[\exp \left(\frac{q\left(V-R_{S} I\right.}{n K_{B} T_{S}}\right)-1\right]-\frac{V+R_{S} I}{R_{P}} \\
& I_{0}=I_{0}\left(T_{1}\right)\left[\exp \left(\frac{V_{O C}\left(T_{1, r e f}\right)}{n K_{B} T_{1, r e f} / q}\right)-1\right]
\end{aligned}
$$

The internal serial resistance RS relative to one cell in open circuit voltage $\mathrm{VOC}$ is:

$$
\begin{aligned}
R_{S}=-\left.\frac{d V}{d I}\right|_{V_{O C}} & -\left(\frac{n K_{o} T_{1, \text { ref }}}{q}\right) \\
& / I_{0}\left(T_{1, r e f}\right) \exp \left(\frac{V_{O C}\left(T_{1, \text { ref }}\right)}{n K_{B} T_{1, r e f} / q}\right)
\end{aligned}
$$

The PV output voltage of the serial cells can be expressed as $\mathrm{V}$ :

$V=N_{S} \frac{n K_{B} T}{q} \ln \left(\frac{I_{S C}-I}{q I_{0}}\right)$

IL varies as a function of the ambient temperature $T$ and of the solar radiation $\mathrm{G}$ as:

$$
I_{\mathrm{L}}=I_{\mathrm{L}}\left(T_{1, r e f}\right)+K_{o}\left(T-T_{1, r e f}\right)
$$


With $\quad K_{o}=\frac{I_{S C}\left(T_{2, r e f}\right)-I_{S C}\left(T_{1, r e f}\right)}{T_{2, \text { ref }}-T_{1, \text { ref }}}$

$I_{\mathrm{L}}=I_{\mathrm{STC}}\left(T_{1, r e f, S T C}\right) \frac{G_{S}}{G_{S T C}}$

The PV system exhibits a nonlinear I(V) characteristic which depend on the temperature and the solar radiation which vary during a day, for exemple, as shown by the figure TempRadiation; where a) and b) show the profile of real irradiation measured and temperature for one day.
The photovoltaic Panel considered, in this paper, contains 36 photovoltaic cells connected in series. To track the Maximum Power Point (MPPT) and achieve the optimum matching, a good control of the DC-DC is necessary. As the temperature, insulation and load vary, an algorithm is used to ensures that the PV module always operates at its maximum power point. The boost converter operation principle is the one of Variable Structure System (VSS). The Switching frequency of the Boost IGBT (changing s) is in general around $\mathrm{fsw}=1 / \mathrm{Ts}=20 \mathrm{kHz}$. We will try to use, in the comparative analysis different frequency values.

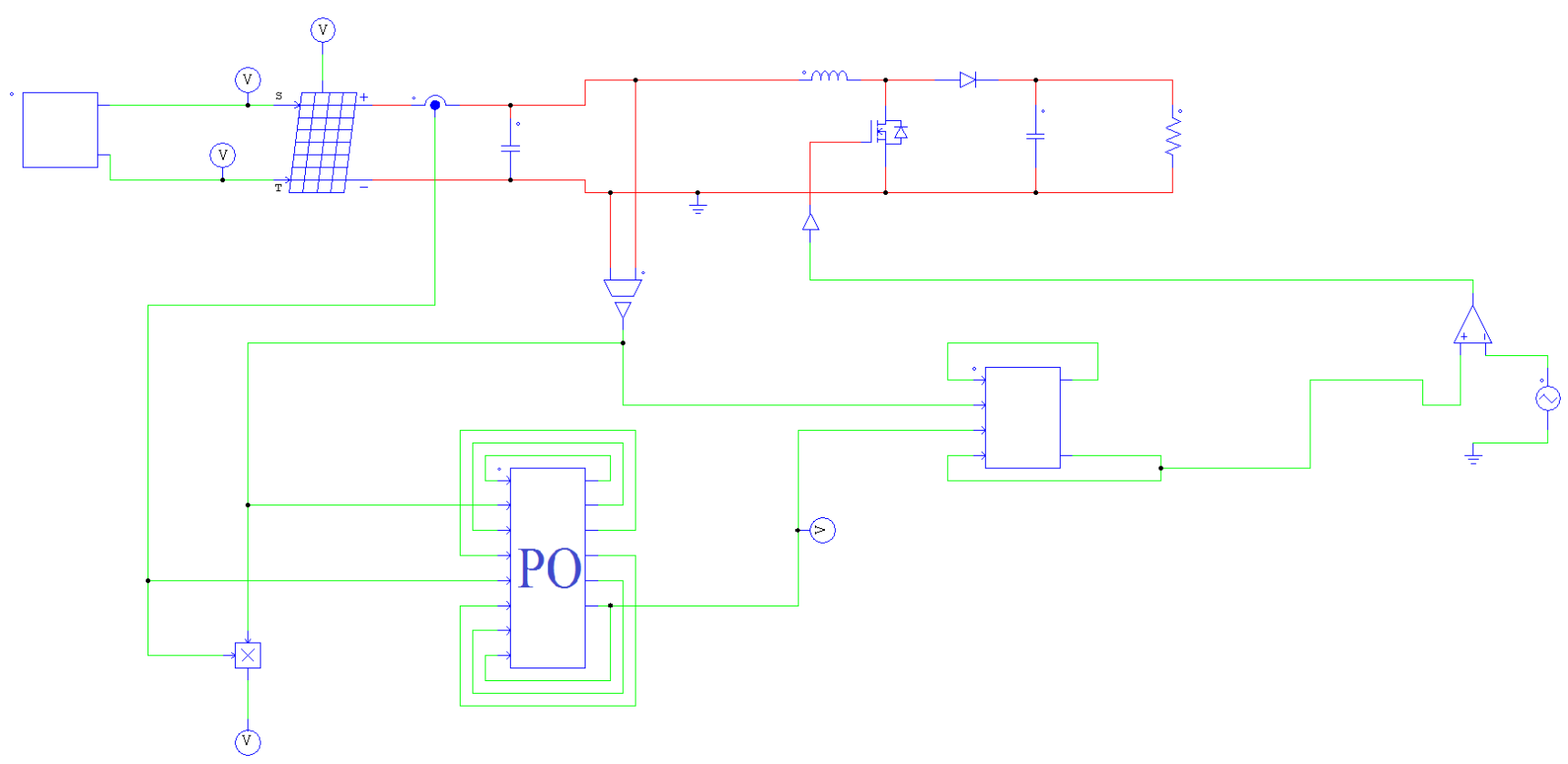

Fig .3 Shows the electric circuit diagram of a PV panel connected to a DC/DC converter with the MPPT control circuit based on PO.

\section{B. The MPPT Controls for PV Systems}

This part reviews 3 of the most frequently used control algorithms to get the maximum power. As presented previously, an MPPT controller is used to increase the PV system efficiency. The principle is to calculate the optimal reference output voltage and/or current which ensures that the PV system operate at its MPP. These techniques are different from each other in many aspects, including simplicity, convergence speed, hardware implementation, sensors required, cost, range of effectiveness and need for parametrization (see eg [Shaefer] for a survey).

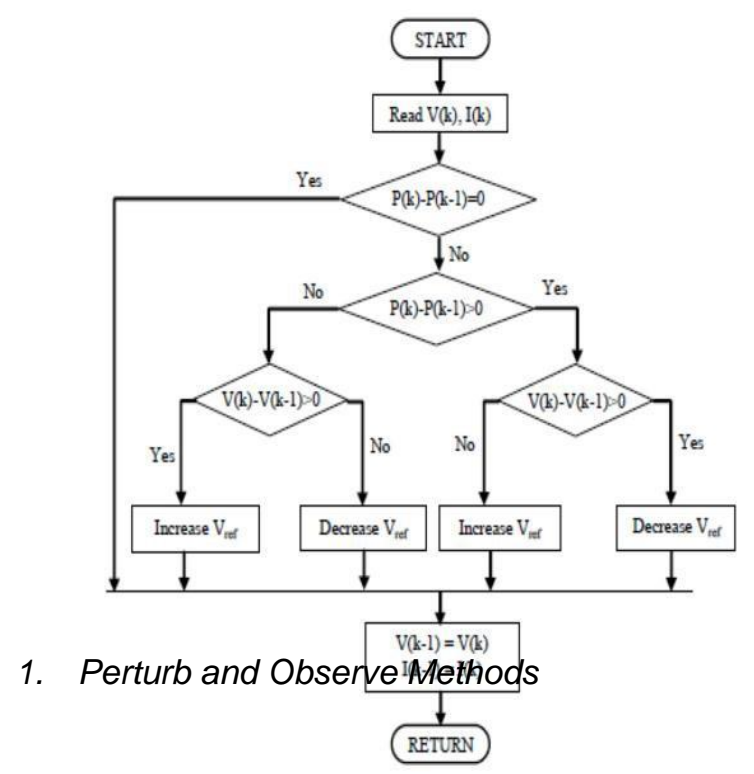


The most commonly used MPPT algorithm is the Perturbation and Observation (PO) due to its easy implementation. It uses the $\mathrm{P}-\mathrm{V}$ characteristics $P p v=f(V)$ of the PV module. Note that, for constant weather conditions, the operating power point $P(n)=V(n) I(n)$ is obtained when the condition $d P / d V=0$ is accomplished. We can calculate the slope $(\mathrm{dP} / \mathrm{dV})$ using consecutive outputs measurements (voltages and output):

$$
\frac{d P}{d V}(n)=\frac{P(n)-P(n-1)}{V(n)-V(n-1)}
$$

- If the operating voltage of the PV array is perturbed in a given direction and DP/DV $>0$, then the perturbation moves the array's operating point toward the MPP. The PO algorithm would then continue to change the PV array voltage in the same direction.

- If $D P / D V<0$ then the change in operating point moves the PV array away from the MPP, and the $\mathrm{PO}$ algorithm reverses the direction of the perturbation [Femia].

Some limitations are encountered such as: oscillations around the MPP in steady state operation, slow response speed, and even tracking in wrong way when atmospheric condition instability [Kim, Liu, Femia].

The duty cycle of the Boost is changed and the process is repeated until the maximum power point has been reached. In actual experiments, the system oscillates around the MPP. To minimize the oscillations amplitude, we can reduce the perturbation step size. However, small step size slows down the convergence of the MPPT.

To solve this problem, we can use smaller perturbation size towards the MPP.

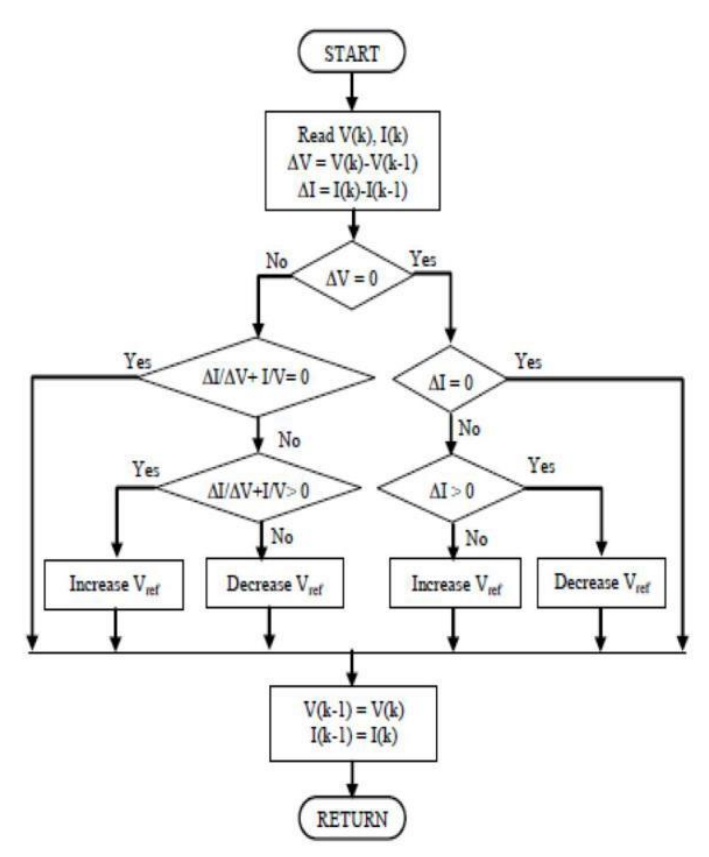

\section{Perturb and Observe Methods}

The incremental conductance (IncCond) [Femia], method is based on the fact that the slope (or the PV conductance $G=d l / d V$ ) of the PV array, in the power curve is zero at the MPP and it is positive (constant) on the left of the MPP. The slope becomes negative on the right of th MPP. These relations can be rewritten in terms of the array current and voltage as:

$\frac{d P}{d V}=\frac{d V I}{d V}=I \frac{d V}{d V}+\mathrm{V} \frac{d I}{d V}=I+\frac{d I}{d V}$

to keep $D P / D V=0$ we need: $G=d l / d V=-I / V ; D P / D V=$ 0 at the MPP

- If $\mathrm{G}=\frac{d I}{d V}>-\frac{I}{V}$ (this means that $d P / d V>0$ ), the operating point is on the left side of the MPP, $\checkmark$ has to be raised.

- If $\mathrm{G}=\frac{d I}{d V}<-\frac{I}{V}(\mathrm{dP} / \mathrm{dV}<0)$, the operating voltage is on the right side of the MPP then V has to be reduced.

voltage is on the right side of the MPP then V has to be reduced.

\section{Hill Climbing Method}

In general the almost applications, use DC-DC converters and DC-AC inverters, as the power interface devices between PV modules and loads. The basic idea of the HC (Hill Climbing) method is the 
same as $P \& O$ method. It tests if $P(n)$ is greater than $\mathrm{P}(\mathrm{n}-1)$ or not, to reach MPP. The PO method uses instead a test on $\mathrm{dP} / \mathrm{dV}$ to determine whether the maximum power point has been found or not. However, the $\mathrm{HC}$ method uses a test condition on $P(n)-P(n-1)$ and uses the duty cycle (D) of these switching mode power interface devices as the decision action parameter for the maximum power point tracking. The figure7 shows a flow diagram of the hill climbing algorithm.

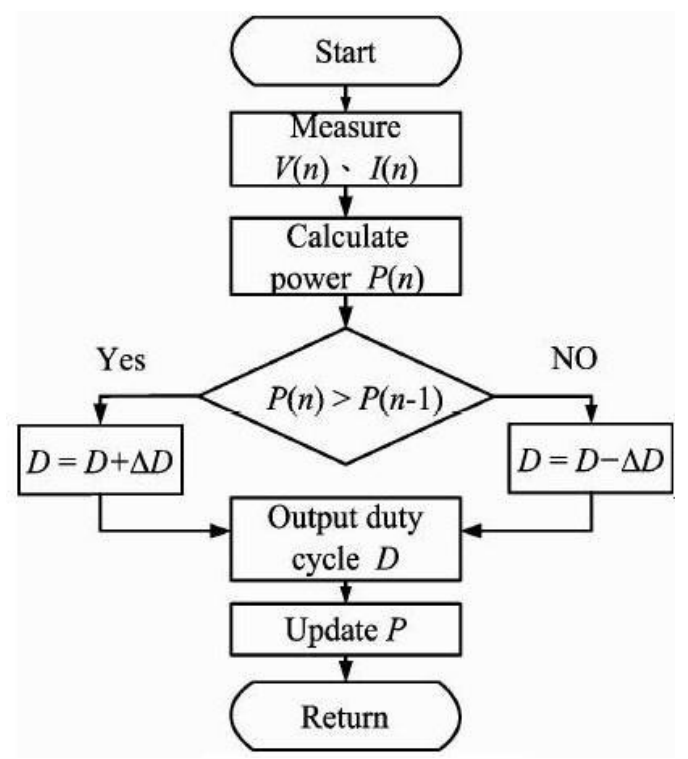

\section{The Proposed VSAS-MPPT Algorithms}

The desired objective to get is that the MPP reached when the maximum power is obtained $(\mathrm{P}(\mathrm{t})=\mathrm{Pmax}$ and $\mathrm{dP} / \mathrm{dt}=0$ ). The power is function of the voltage $\mathrm{V}$, the current $I$ and the time $t$, then the required Maximum Power Point to Track is really defined by the following objective function:

$$
\frac{d P}{d t}=\frac{d V I}{d t}=I \frac{d V}{d t}+V \frac{d I}{d t}=0
$$

Let us consider the control in case of discrete time, then the fetched MPPT may be defined by $\Delta P(k)=0$,

$$
\begin{aligned}
& \left\{\begin{array}{c}
\Delta I=I_{P V}(k)-I_{P v}(k-1) \\
\Delta V=V_{P V}(k)-V_{P V}(k-1) \\
\Delta P=P_{P V}(k)-P_{P V}(k-1) \\
P_{P V}(k)=V_{P V}(k) \cdot I_{P V}
\end{array}\right. \\
& \Delta P(k)=I(k) \cdot \Delta V(k)+V(k) \cdot \Delta I(k) \\
& \Delta P(k)=I(k) \cdot u_{1}(k)+V(k) \cdot u_{2}(k)
\end{aligned}
$$

The two control variables are then $u 1(k)=\Delta V(k)$ (the voltage variation) and $u 2(k)=\Delta l(k)$ (the current variation).

\section{RUCA: Robust Unified Control Algorithm}

For the proposed RUCA algorithm, both control inputs can be used if we look for adjusting both variables ( $\mathrm{V}$ and I), either at each control step or alternatively. It can be noticed that the previous algorithms can be considered as particular cases of this one, when simplifying the proposed control method. $P$ max is a constant chosen greater than the maximum power in any weather condition $P \max \geq P(t)$. Let us then consider the Lyapunov like function

$$
\mathrm{W}(\mathrm{t})=\left(P_{\max }^{2}-\mathrm{P}(\mathrm{t})^{2}\right)>0
$$

which is strictly positive everywhere $(\forall t, \forall I, \forall V)$. The derivative of the proposed Lyapunov function $W(t)=($ $\mathrm{P}^{\wedge} 2 \rrbracket\left[\max -\llbracket P(\mathrm{t}) \rrbracket^{\wedge} 2\right)>0$, is

$\dot{W}(\mathrm{t})=-\mathrm{P}(\mathrm{t}) \frac{d P(t)}{d t}=-\mathrm{P}(\mathrm{t})\left(I \frac{d V}{d t}+V \frac{d I}{d t}\right)$

$\left.\dot{W}(\mathrm{t})=-I^{2} V \frac{d V}{d t}-V^{2} I \frac{d I}{d t}\right)$

$\mathrm{t}$ can be made negative by choosing the appropriate control laws $u 1(k)=\Delta V(k)$ and $u 2(k)=\Delta l(k)$ to get a decreasing Lyapunov function. The RUCA uses two control inputs which can be done either simultaneously or alternatively or one of them can be frozen depending on the needed voltage or current. Choosing

$\mathrm{u} 1(\mathrm{k})=\mathrm{Ka} \Delta \mathrm{P}(\mathrm{k}) \operatorname{sign}(\Delta \mathrm{V}(\mathrm{k}))$

$\mathrm{u} 2(\mathrm{k})=\mathrm{K} \_2 \mathrm{a} \_2 \Delta \mathrm{P}(\mathrm{k}) \operatorname{sign}(\Delta \mathrm{l}(\mathrm{k}))$

ensures that $W^{\prime}(t)<0$ and then the convergence of the RUCA algorithm. This proves, theoretically also the convergence of the MEPO algorithm which follows. We can use both inputs or only one of them either, in a first case $\mathrm{u} 1(\mathrm{k})=\mathrm{Ka} \Delta \mathrm{P}(\mathrm{k}) \operatorname{sign}(\Delta \mathrm{V}(\mathrm{k}))$, or in the second case $u 2(k)=K \_2 \quad a \_2 \quad \Delta P(k) \operatorname{sign}(\Delta l(k))$. In control context, the previously presented MPPT controllers use only one control variable $u 1$ or $u 2$ and impose the second to be zero. The implementation of the proposed enhanced MPPT controller RUCA can be summarised as follows:

- The reference voltage is set be equal to the double of the PV open circuit voltage.

- Measurement of the of input signals (PV voltage, 
PV current and Load voltage).

- Estimate the PV power at the sample time $k$ : PPV $(k)=\operatorname{lpv}(k) \cdot \operatorname{Vpv}(k)$

- Calculate the PV current and PV power increments (see equation eq:optim).

\section{MEPO: Modified Enhanced PO Algorithm}

If we take as input $\mathrm{u} 1(\mathrm{k})$ and put a constant current $\mathrm{u} 2(\mathrm{k})=0$, which means that the voltage is perturbed and the current is fixed $u 2(k)=\Delta l(k)=0$, we are in the same configuration as the $\mathrm{PO}$ algorithm. We propose, as a Modified Enanced PO Algorithm which will be more robust, the reference voltage is given by Vref $=\mathrm{Vk}+\mathrm{Ka} \Delta \mathrm{P}(\mathrm{k}) \operatorname{sign}(\Delta \mathrm{V}(\mathrm{k}))$ Knowing that we impose $\Delta \mathrm{l}(\mathrm{k})=0$, we get for the proposed MEPO control algorithm we take $\mathrm{u} 1(\mathrm{k})=\mathrm{Ka} \Delta \mathrm{P}(\mathrm{k}) \operatorname{sign}(\Delta \mathrm{V}(\mathrm{k}))$ and $u 2(k)=\Delta l(k)=0$. The reference voltage $\operatorname{Vref}(k)$ is calculated as below, where $\alpha$ is a gain weighting the perturbation variation step. Note that $\Delta \mathrm{Vref}=$ asign $(\Delta P(k) \Delta V(k))$ produces exactly the same result as the classical $P O$ algorithm with a much simpler implementation. This method gives an enhanced variable step size algorithm. The step size is adjusted in proportionally to the power variation produced in the previous step. The adaptive step adjustment gain $\mathrm{K}$ is used with $\Delta P(k)$, for weighting the variation (Voltage perturbation) step. It is useful for oscillation avoidance, fast convergence and noise sensitivity reduction. We can also use only the control variable u2 $(k)=\Delta l(k)$ (and put $u 1(k)=0$ ), the current is perturbed and the voltage is fixed $\Delta \mathrm{V}(\mathrm{k})=0$.

\section{Comparative Simulations and Tests}

The simulation was performed under Psim software as shown in figure 3 . The physical model of a PV panel is used. The panel is considered to have 36 cells. A boost converter is built using a MOSFET as a switch. The load is a $100 \Omega$ resistor. The algorithms are implemented in a $\mathrm{C}$ block and the duty cycle is calculated from Vref using another $C$ block. The actual, measured irradiation and panel temperature are read from a txt file as inpt to the simulation.

\section{MPPT Alghorithms Comparison}

In this study we compare four MPPT algorithms under the same experimental conditions. The first algorithm called $\mathrm{P} \& \mathrm{O}$ stands for perturb and observe. The second algorithm called IncCond stands for incremental conductance. The third algorithm called MEPO stands for Modified Enhanced Perturb and Observe (from VSAS- MPPT). And the fourth algorithm called RSMCA (from VSAS-MPPT approach) stands for Robust Sliding Mode Control Algorithm. Note that RUCA algorithm is simply combining use of the two VSAS MPPTs alternatively.

The comparison is made under changing values of irradiation and temperature. Two cases are considered: first we update the irradiance and temperature each time without interpolation to create sudden variation in power output, second we interpolate the values of irradiance and temperature to create quasi-continuous irradiation and temperature. At the end we use real measured data for simulation. In this study we focus on the PWM commutation frequency of the MPPT algorithm.

\section{Zero Order Hold Interpolation Analysis}

We perform many simulations with varying irradiance and temperature. The values are not interpolated causing sudden variation in power output. For high MPPT algorithm frequencies $(25 \mathrm{~Hz}, 50 \mathrm{~Hz}, 100 \mathrm{~Hz})$ no difference in power output is noted between the four algorithms. After a change in environmental conditions that makes an increase in power output, MEPO algorithm may present an oscillation because it is based on the value of DP and not on the sign of DP. At high irradiances, the RSMCA algorithm present oscillation caused by the gain in calculation of Vref.For low frequencies $(5 \mathrm{~Hz}, 10 \mathrm{~Hz}, 12.5 \mathrm{~Hz})$, the MEPO and the RSMCA algorithms excel the PO and IncCond algorithms. We can see in figure 2 that the $\mathrm{PO}$ power and the IncCond power are too far from the maximum power that can be generated from the panel. This is due to the fixed or small step size of the Vref. We must recall that the MEPO and the RSMCA algorithms also converge rapidly to the maximum power after the start of the simulation.

\section{First Order Interpolation Analysis}

When interpolating data for irradiance and temperature (approaching real conditions), we can see that that the difference between $\mathrm{PO}$ and IncCond algorithms and MEPO and RSMCA algorithms are emphasized when we have high variation of environmental conditions and low algorithm frequency. 
(c)

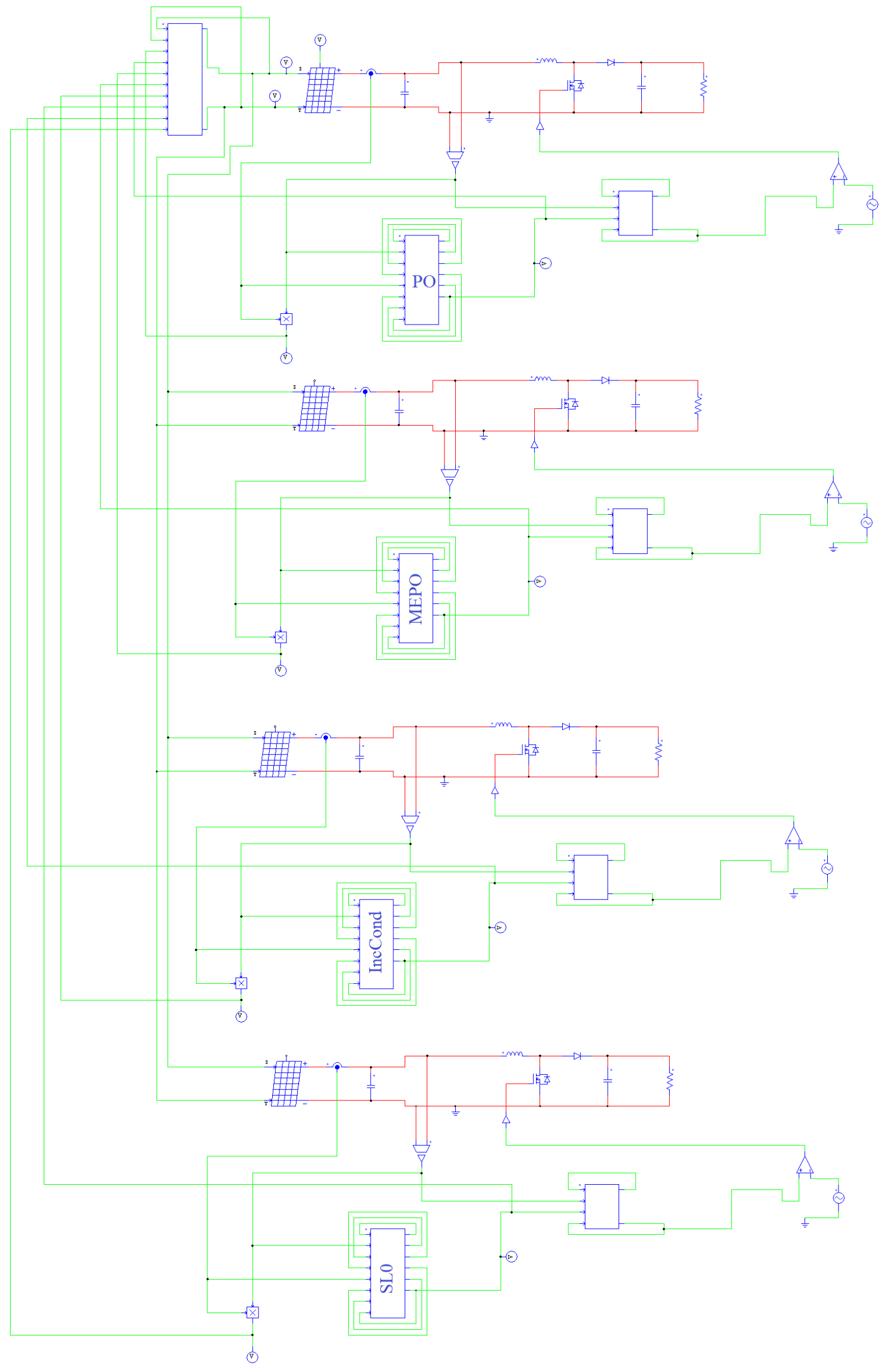

Fig .4. Shows the electric circuit diagram of the 4 MPPT algorithms 


\section{Real Data Analysis}

In this simulation we take real data measured for one day. We choose 20 minutes that present high fluctuations of irradiance $(878 \mathrm{~W} / \mathrm{m} 2-126 \mathrm{~W} / \mathrm{m} 2)$ and temperature $\left(26^{\circ} \mathrm{C}-14^{\circ} \mathrm{C}\right)$. The data is available each $5 \mathrm{~min}$ which mitigates the high variation in environmental conditions. This is why the algorithms results are almost identical even for low frequency.

\section{CONCLUSION}

In this paper, a new Robust MPPT algorithm is proposed to optimize the production of a photovoltaic (PV) chain. We developed a new technique to design the maximum power point tracking (VSAS-MPPT) based on Variable Structure Automatic Systems approach. This approach generalizes the sliding mode control to systems with commutations in a simplified technique, easy to implement. New and very efficient algorithms are proposed from VSAS-MPPT approach:

- the MEPO (Modified Enhanced Perturb and Observe)

- the RUCA algorithm (Robust Unified Control Algorithm).

\section{$\bullet$}

The MPP is computed online using a very simple algorithm which uses two control inputs (one in current and one in voltage). The other algorithms like
Perturb and Observe (PO), Hill Climbing, Incremental Encoder (InCond) and SMC look as particular cases of the proposed Algorithm called RUCA (Robust Unified Control Algorithm). The proposed MPPT has several advantages: simplicity, high convergence speed, and is independent on PV array characteristics. We study and compare execution efficiency for the proposed VSAS-MPPT algorithms to the other methods, including Perturbation and Observation (P\&O).

Realistic simulations are presented to show ease of implementation of our new algorithms, and compare its efficiency and accuracy to other MPPTs. The obtained results prove that the MPPT is tracked even under sudden change of irradiation level or temperature. In our comparative tests, a particular case (use only voltage input), called the Modified and Enhanced Perturb and Observe Algorithm (MEPO), is shown to be the most fast and efficient, despite using low frequency commutation and sudden fast temperature and irradiation changes. The proposed MPPT has several advantages: simplicity, high convergence speed, oscillation free and is independent on PV array characteristics. In summary the best algorithms are those designed using the SASV-MPPT approach and considering that the system can move from one characteristic to another. The proposed algorithms are the most efficient despite using low frequency commutation. They are the faster converging. The simulations was performed under PSIM software to use realistic physical models.
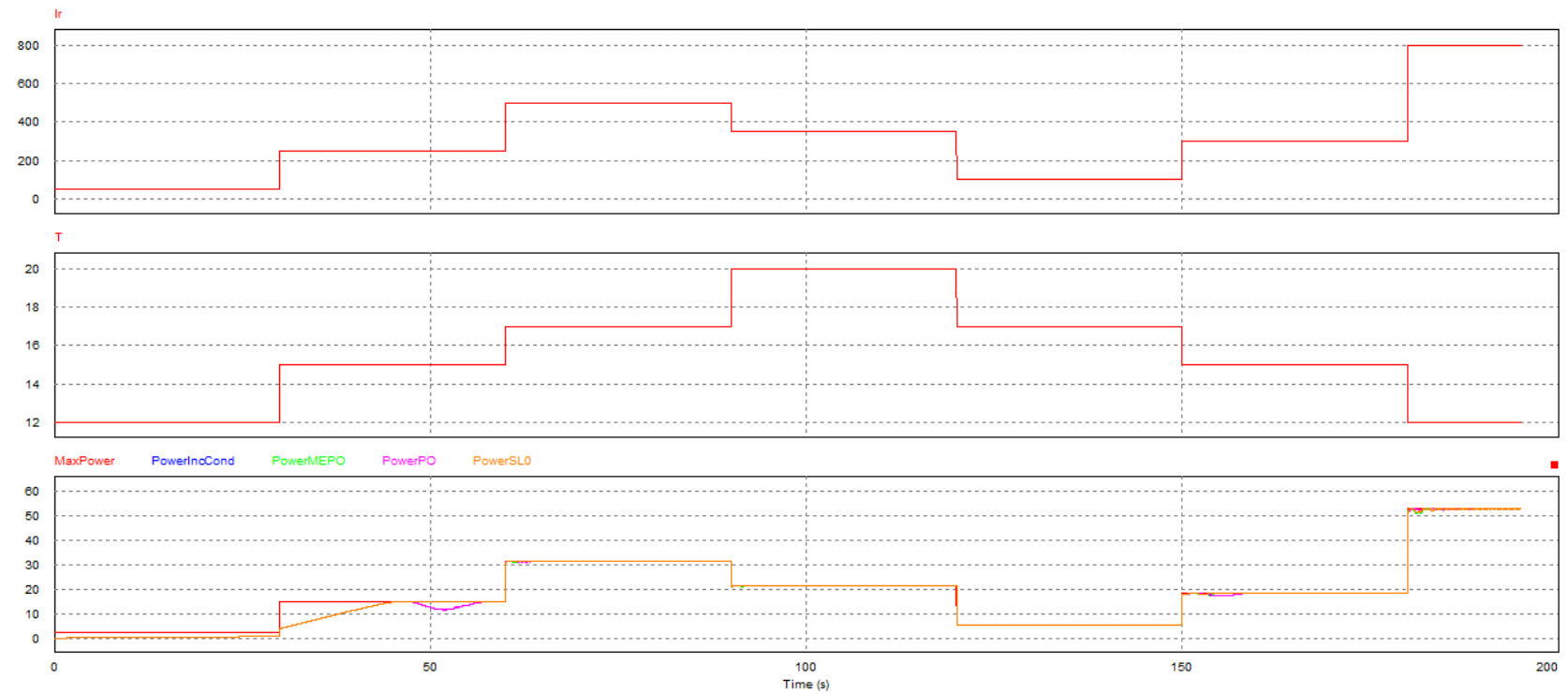

Fig .5. Sudden variation of irradiation and T with frequency $(100 \mathrm{~Hz})$ 

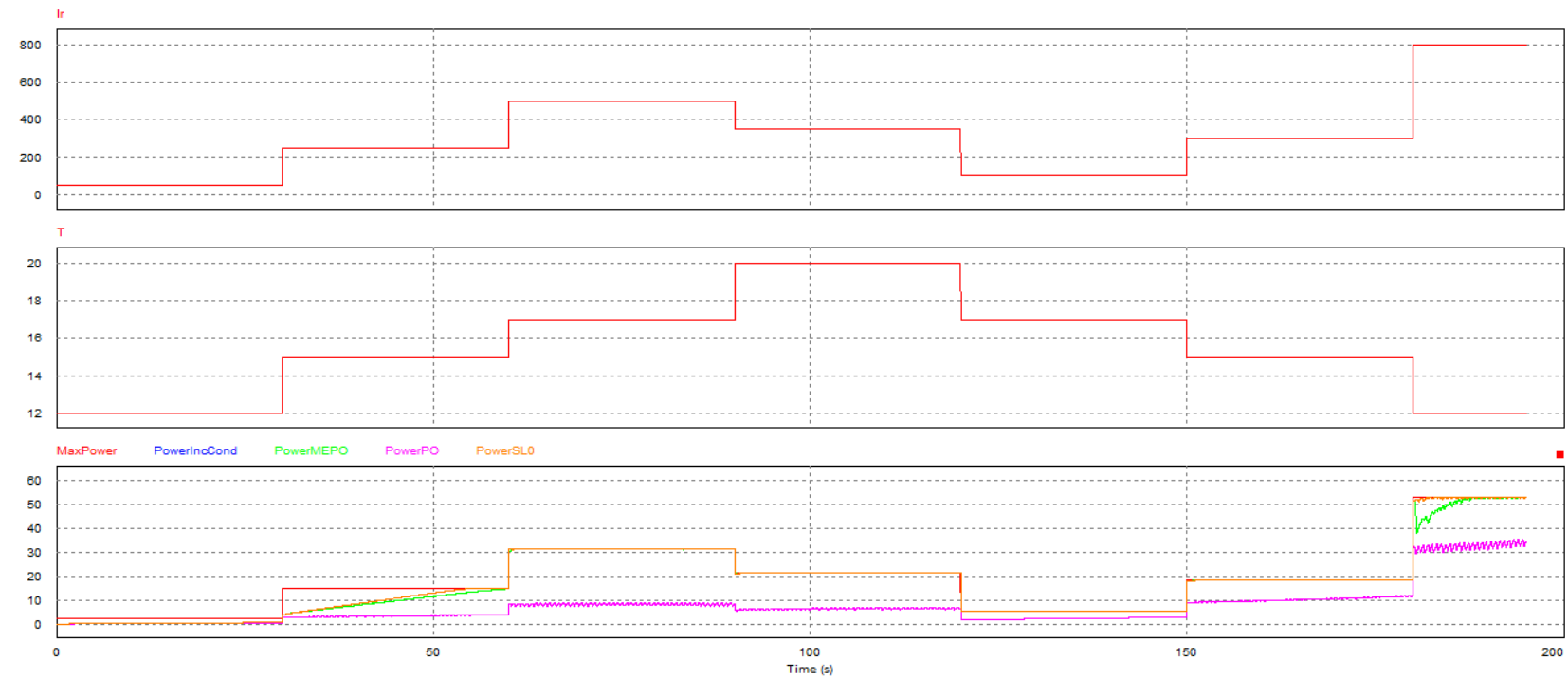

Fig .6. Variation of irradiation and temperature with low frequency $(5 \mathrm{~Hz})$
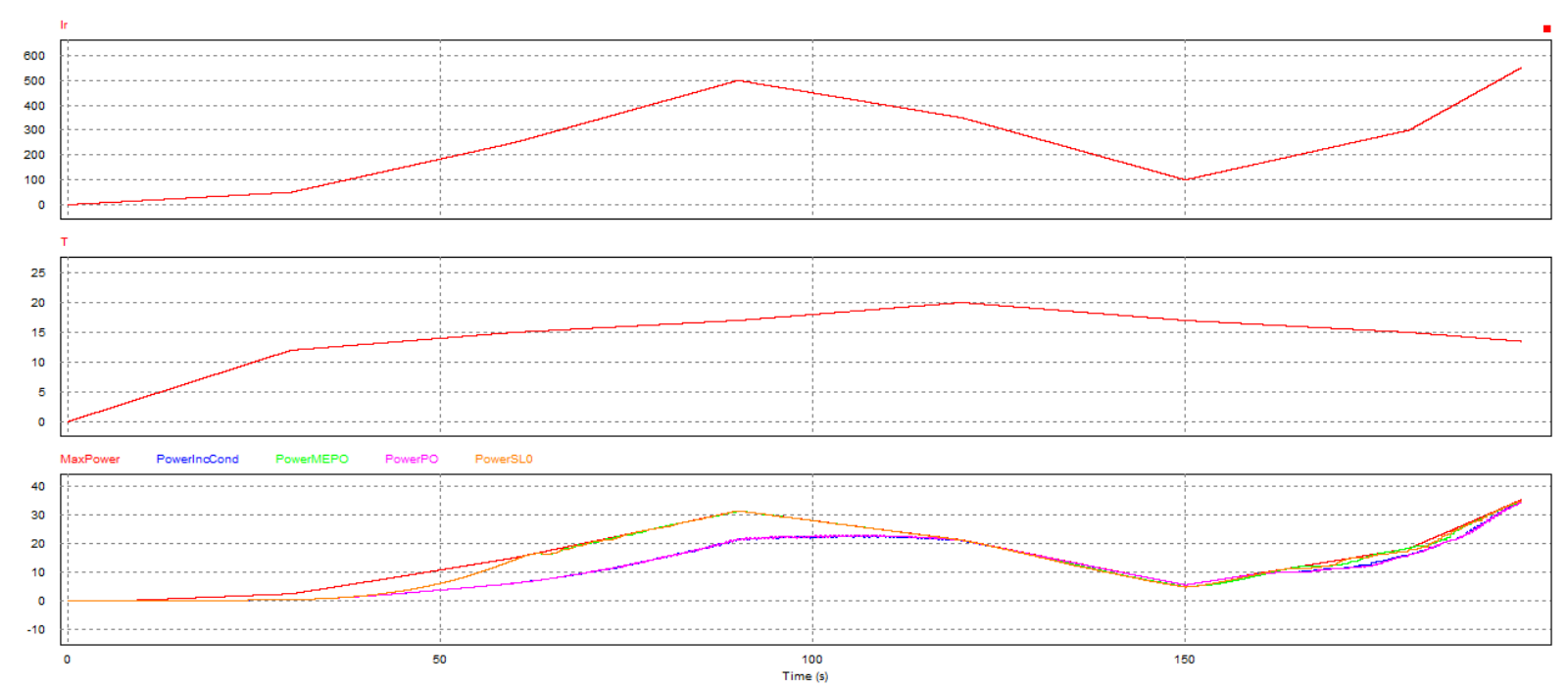

Fig .7. Interpolated variation of irradiation and T with low frequency $(10 \mathrm{~Hz})$
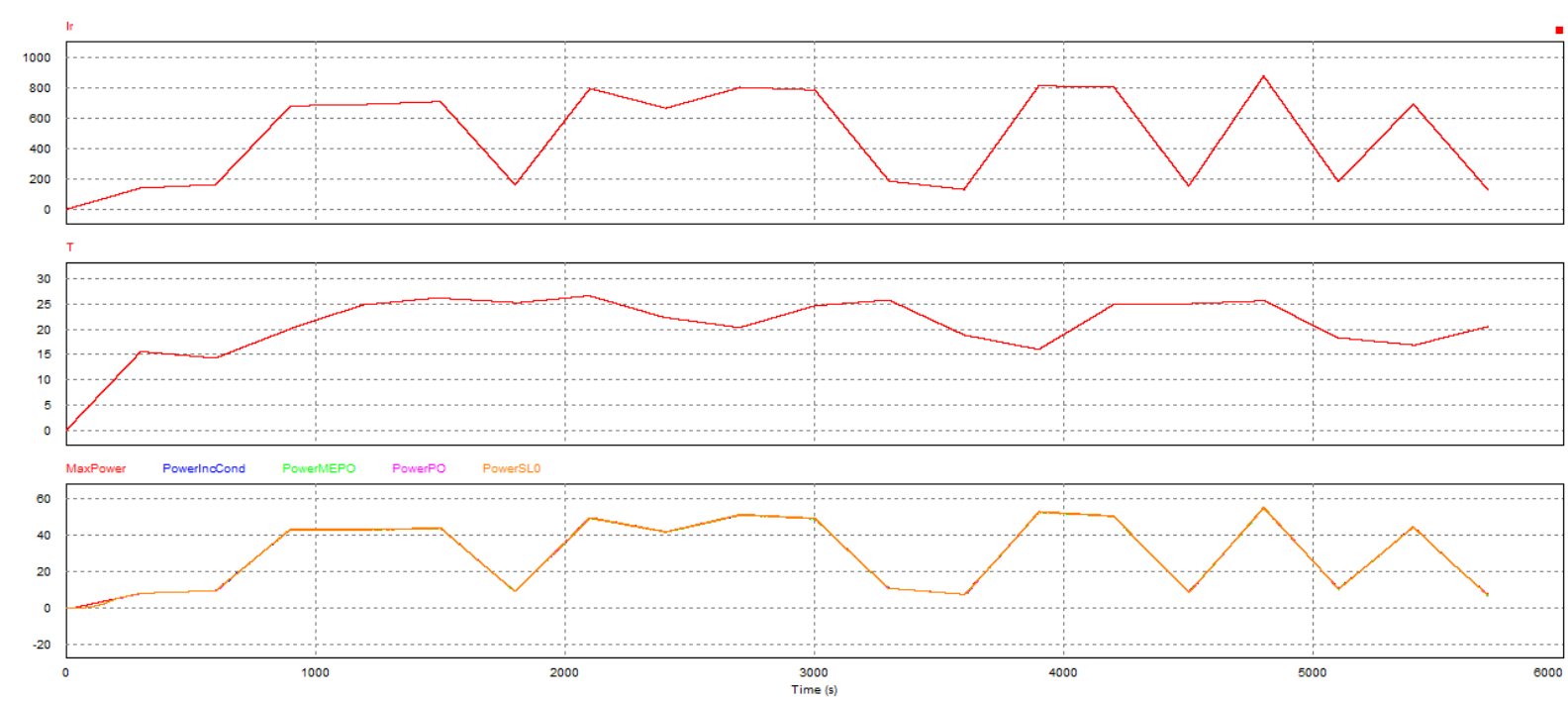

Fig .8. Real data interpolated with low algorithm frequency $(10 \mathrm{~Hz})$ 


\section{REFERENCES}

[1] M'Sirdi, N. K., Nehme, B. and Rabhi, A. (November 2014) The Best MPPT Algorithms by VSAS approach for Renewable Energy Sources (RES). EFEA 2014, international IEEE conference PARIS.

[2] Mutoh, N. Ohno, M. and Inoue, T. (June 2006) A method for MPPT control while searching for parameters corresponding to weather conditions for PV generation systems. IEEE Transactions on Industrial Electronics, vol.53, no.4, pp.10551065.

[3] Wang, N. C., Sun, Z., Yukita, K., Goto, Y. and Ichiyanagi, K. (March 2010) Research of PV model and MPPT methods in Matlab. AsiaPacific Power and Energy Engineering Conference (APPEEC 2010), pp.1-4, 28-31.

[4] Amei, K., Takayasu, Y., Ohji, T. and Sakui, M. (2002) A Maximum Power Control of Wind Generator System Using a Permanent Magnet Synchronous Generator and a Boost Chopper Circuit. IEEE Power Conversion Conference, vol. 3, , pp. 1447- 1452.

[5] Yu, T. C., and Shen,Y.T. (Nov. 2009) Analysis and Simulation of Maximum power point tracking for photovoltaic systems. Proceedings of the 30th ROC Symposium on Electrical Power

Engineering, Taoyuan, Taiwan, pp. 92-96.

[6] Tavares, C. A. P., Leite, K. T. F., Suemitsu, W. I. and Bellar, M. D. (Nov. 2009) Performance Evaluation of Photovoltaic Solar System with Different MPPT Methods, Industrial Electronics, 2009. IECON '09. 35th Annual Conference of IEEE, pp.719-724.

[7] Hua, C., Lin, J., Shen, C. (1998) Implementation of DSP-Controlled Photovoltaic System with Peak Power Tracking. IEEE Trans. On Industrial Electronics, Vol. 45, No. 1, pp. 99-107.

[8] Liu, F., Kang,Y., Zhang, Y., and Duan, S., (June 2008) Comparison of $P \& O$ and hill climbing MPPT methods for grid-connected PV converter. 3rd IEEE Conference on Industrial Electronics and Applications, (ICIEA 2008), pp.804-807, 3-5.

[9] Hua, C. C., Lin, J. R. (June 2001) Fully Digital Control of Distributed Photovoltaic Power
Systems. Proceedings of IEEE International Symposium on Industrial Electronics (ISIE 2001), vol. 1, pp. 1-6.

[10] Xiao,W. (July 2003) A Modified Adaptive Hill Climbing Maximum Power Point Tracking Control Method for Photovoltaic Power System. Master Thesis, The University of British Columbia,

[11] Liu X., Lopes L.A.C. ( June 2004) An Improved Perturbation and Observation Maximum Power Point Tracking Algorithm for PV Arrays. Power Electronics Specialists Conference, 2004. PESC 04. 2004 IEEE 35th Annual Volume 3, pp. $2005-2010$.

[12] Hohm, D. P., Ropp, M. E. (January 2003) Comparative Study of Maximum Power Point Tracking Algorithms. Progress in Photovoltaics: Research and Applications, vol. 11 , no. 1 , pp. 47-62,

[13] Ibrahim, H. E. and Houssiny, F. F., (August 1999) Microcomputer Controlled Buck Regulator for Maximum Power Point Tracker for DC Pumping System Operates from Photovoltaic System. Proceedings of the IEEE International Fuzzy Systems Conference, Vol. 1, pp. 406-411.

[14] Midya, P., Kerin, P. T., Turnbull, R. J., Reppa, R. and Kimball, J. (1996) Dynamic Maximum Power Point Tracker for Photovoltaic Applications. Proceedings of the IEEE Power Electronics Specialists Conference, PESC, Vol. 2, pp. 17101716.

[15] Kuo, Y. C., Liang, T. J. and Chen, F. C. (2001) Novel Maximum-Power-Point-Tracking Controller for Photovoltaic Energy Conversion System. IEEE Transactions on Industrial Electronics, Vol. 48, pp. 594- 601.

[16] Kaiser, M., Aditya, S. and Mazumder, R.( July 2006) Performance Evaluation of a Maximum Power Point Tracker (MPPT) for Solar Electric Vehicle Using Artificial Neural Network. Daffodil International University Journal Of Science And Technology, vol. 1 , issue 1 .

[17] Xiao, W. and Dunford, W. G. (2004) A modified adaptive hill climbing MPPT method for photovoltaic power systems," 35th. Annual IEEE 
Power Electron. Specialists Conf., pp. 19571963.

[18] Tina, G.M. and Scrofani, S.( May 2008) Electrical and Thermal Model for PV Module Temperature Evaluation. IEEE Electrotechnical Conference. pp. 585-590.

[19] Schaefer, J. (June 1990) Review of Photovoltaic Power Plant Performance and Economics, IEEE Trans. Energy Convers., vol. EC-5, pp 232-238.

[20] Tse, K. K., Ho, M. T., Henry, S., Chung, H. and Hui, S. Y. (November 2002) A Novel Maximum Power Point Tracker for PV Panels Using Switching Frequency Modulation. IEEE Transactions on Power Electronics, Vol. 17, No.6.

[21] Calavia, M., Perie, J.M., Sanz, J.F. and Sallan, J. (March 2010) Comparison of MPPT Strategies for Solar Modules. International Conference on Reneweble Energies and Power Quality, Granada (Spain),

[22] Femia, N., Petrone, G., Spagnuolo, G. and Vitelli, M. (June 2004) Optimizing duty-cycle perturbation of P\&O MPPT technique. Power Electronics Specialists Conference, 2004. PESC 04. 2004 IEEE 35th Annual Volume 3, pp.1939 -1944 .

[23] Femia, N., Petrone, G., Spagnuolo, G. and Vitelli, M. (July 2005) Optimization of Perturb and Observe Maximum Power Point Tracking Method. IEEE Transactions on Power Electronics, Vol. 20, No. 4.

[24] Fangrui, L., Shanxu, D., Fei, L., Bangyin, L. and Yong, K. (July 2008) A Variable Step Size INC MPPT Method for PV Systems. IEEE Transactions on Industrial Electronics, Vol. 55, No. 7.

[25] Chao, K.H. and Lee, Y.H. (Volume
2012) A Maximum Power Point Tracker with Automatic Step Size Tuning Scheme for Photovoltaic Systems. International Journal of Photoenergy.

[26] Zoua,Y., Yua,Y., Zhangb, Y. and Luc, J. (2012) MPPT Control for PV Generation System Based on an Improved Inccond Algorithm. Procedia Engineering Vol. 29, pp.105-109.

[27] Chen, C. H. (2002) Maximum Power Tracking for Photovoltaic Power System. In Conf. Record of the 37th IAS Annual Meetinglnd. Applicat. Conf., pp. 1035-1040.

[28] Walker, G. (2001) Evaluating MPPT Converter Topologies Using a MATLAB PV Model. Journal of Electrical \& Electronics Engineering, Australia, IEAust, vol.21, No. 1, pp.49-56.

[29] Veerachary, M., Senjyu, T. and Uezato, K. (July 2002) Feedforward Maximum Power Point Tracking of PV Systems Using Fuzzy Controller. IEEE Transactions on Aerospace and Electronic Systems, Vol. 38, 3, 969-981.

[30] Miao, Z., Jie, W. et al.,( 2004) The Application of Slide Technology in PV Maximum Power Point Tracking System. Fifth WorldCongress on Intelligent Control and Automation, WCICA.

[31] Kim, T. Y., . Ahn, H. G., Park, S. K. and Lee, Y. K. (2001) A Novel Maximum Power Point Tracking Control for Photovoltaic Power System Under Rapidly Changing Solar Radiation. In IEEE International Symp. On Ind. Electron, pp. 10111014.

[32] MATLAB Simulink. Creating Graphical User Interfaces. Version 7.9 [Online]. Available : http://www.mathworks.com/access/ helpdesk/ help/ techdoc / creating_guis/ bqz79mu.html. 